\title{
Improved pre-operative diagnostic accuracy for low-grade prosthetic joint infections using second-generation multiplex Polymerase chain reaction on joint fluid aspirate
}

\author{
Christian Suren ${ }^{1} \cdot$ Susanne Feihl ${ }^{2} \cdot$ Sabrina Cabric $^{3} \cdot$ Ingo J. Banke ${ }^{1}$ - Bernhard Haller ${ }^{4}$. Andrej Trampuz ${ }^{3}$. \\ Rüdiger von Eisenhart-Rothe ${ }^{1} \cdot$ Peter M. Prodinger ${ }^{1}$
}

Received: 20 December 2019 / Accepted: 26 March 2020 / Published online: 15 April 2020

(C) The Author(s) 2020

\begin{abstract}
Background A major obstacle for the treatment of prosthetic joint infection (PJI) is the identification of the underlying causative organism. While the diagnostic criteria ruling PJI in or out have become ever more accurate, the detection of the causative pathogen(s) still relies mostly on conventional and time-consuming microbial culture. The aim of this study was to evaluate the diagnostic potential of a second-generation multiplex PCR assay (Unyvero ITI G2, Curetis AG, Holzgerlingen, Germany) used on synovial fluid specimens. Our hypothesis was that the method would yield a higher diagnostic accuracy in the pre-operative workup than synovial fluid culture. Thus, a more precise classification of septic and aseptic prosthesis failure could be achieved before revision surgery.

Methods Prospectively collected frozen joint fluid specimens from 26 patients undergoing arthroplasty revision surgery of the hip or knee were tested as per the manufacturer's protocol. Sensitivities, specificities, positive and negative predictive values as well as positive and negative likelihood ratios with corresponding confidence intervals were estimated using the statistical software $R$. A combination of the serum C-reactive protein (CRP) level, leukocyte count, erythrocyte sedimentation rate, joint fluid culture, tissue biopsy culture, and tissue biopsy histology served as the gold standard.

Results Of the 26 patients included in the study, 15 were infected and 11 were aseptic. Conventional joint fluid culture showed a sensitivity of 0.67 and a specificity of 0.91 . Joint fluid multiplex PCR yielded a sensitivity of 0.8 and a specificity of 1.0 .

Conclusions Using the second-generation Unyvero ITI cartridge on joint fluid aspirate for the detection of prosthetic joint infection, we were able to achieve a higher diagnostic accuracy than with conventional culture. We conclude that to improve pathogen detection before revision surgery, this method represents a valuable and practicable tool.
\end{abstract}

Keywords PJI $\cdot$ Polymerase chain reaction, diagnostic $\cdot$ Diagnosis $\cdot$ Pre-operative $\cdot$ Arthrocentesis $\cdot$ Synovial fluid $\cdot$ Causative organism $\cdot$ Agent $\cdot$ Detection $\cdot$ DNA $\cdot$ Bacteria $\cdot$ Bacterial

Christian Suren

christian.suren@mri.tum.de

1 Klinik und Poliklinik für Orthopädie und Sportorthopädie, Klinikum rechts der Isar der Technischen Universität München, Ismaninger Str. 22, 81675 Munich, Germany

2 Institut für Medizinische Mikrobiologie, Immunologie und Hygiene, Technische Universität München, Trogerstr. 30, 81675 Munich, Germany

3 Centrum für Muskuloskeletale Chirurgie (CMSC), Charité-Universitätsmedizin Berlin, Charitéplatz 1, 10117 Berlin, Germany

4 Institut für medizinische Informatik, Statistik und Epidemiologie, Technische Universität München, Grillparzerstr. 18, 81675 Munich, Germany

$\begin{array}{ll}\text { Abbreviations } \\ \text { CNS } & \text { Coagulase-negative staphylococci } \\ \text { CRP } & \text { C-reactive protein } \\ \text { DNA } & \text { Deoxyribonucleic acid } \\ \text { EBJIS } & \text { European Bone and Joint Infection Society } \\ \text { ESR } & \text { Erythrocyte sedimentation rate } \\ \text { ITI } & \text { Implant and tissue infection (cartridge) } \\ \text { LR } & \text { Likelihood ratio } \\ \text { MSIS } & \text { Musculoskeletal Infection Society } \\ \text { NPV } & \text { Negative predictive value } \\ \text { PCR } & \text { Polymerase chain reaction } \\ \text { PJI } & \text { Prosthetic joint infection } \\ \text { PPV } & \text { Positive predictive value } \\ \text { SLIM } & \text { Synovia-like interface membrane }\end{array}$




\section{Introduction}

Prosthetic joint infection (PJI) is a serious complication of arthroplasty procedures with devastating consequences for patients and healthcare systems. The diagnosis of PJI is still challenging. As there is no single diagnostic parameter available, the diagnosis is made under the consideration of several pre- and intra-operative criteria [1-5]. However, the identification of the underlying pathogen still relies on standard cultures that are prone to false-negative results in the instance of fastidious organisms or false-positive results when the samples are contaminated [6-8]. Additionally, most sets of diagnostic criteria rely on the assessment of information gained intra-operatively, such as tissue biopsies, the sonication of explanted components, and histological workup of the synovia-like interface membrane (SLIM) [2, 9-14]. Thus, the diagnostic process that is set into motion pre-operatively might lack adequate information for a conclusive diagnosis before surgery [10]. As a consequence, infections can be missed, resulting in inadequate treatment, eventually leading to persistent infection with additional patient morbidity and the necessity of further surgical interventions [15]. On the other hand, infections can be falsely assumed, leading to overtreatment and surgery-related morbidity [16-18]. Therefore, more accurate diagnostic methods are needed not only to protect patients from harm but also to plan effective treatment strategies. Recently, molecular diagnostic methods such as polymerase chain reaction (PCR) have been used in this context [19-21]. With this method, the time required to identify the bacterium causing the infection can be reduced considerably. Furthermore, previous antibiotic treatment should have little or no impact on the identification process, as PCR does not necessarily require viable bacteria [22]. However, conventional broad-range PCR (16S ribosomal DNA PCR) is limited due to false-positive results from contamination and difficulties in the detection of mixed infections [23-26]. Multiplex PCR aims to balance this disadvantage by enabling the simultaneous detection of a whole panel of potentially causative organisms [22, 25, 27].

Again, the value of this diagnostic method depends in part on where in the diagnostic cascade it is put to use. While the combination of all conventional pre-operative and intraoperative diagnostic measures yields a sufficient diagnostic accuracy and the chance of the identification of the underlying organism, the identification of the bacterium in conventional cultures of synovial fluid collected pre-operatively often fails $[3,26,28,29]$. This pre-operative diagnostic gap is reflected in the recently published diagnostic algorithm based on the 2018 MSIS criteria by Parvizi et al., in which the fulfilment of only some of the minor criteria leading to a score of $2-5$ points is considered inconclusive, requiring the collection of tissue biopsies and histological analysis during surgery to completely rule out infection [10].
Unyvero (Curetis AG, Holzgerlingen, Germany), a commercially available automated multiplex PCR assay, has been evaluated with favourable results on synovial fluid, tissue and sonication fluid specimens in prosthetic joint infections [25, 30-36]. The new ITI (Implant and Tissue Infection) G2 cartridge generation introduced in 2016 offers an expanded panel of microorganisms and an enhanced sensitivity to detect fastidious organisms such as Cutibacterium acnes (formerly Propionibacterium acnes) (Tables 1 and 2). Our hypothesis was that the expanded panel of organisms would yield a higher diagnostic accuracy in the pre-operative workup. Thus, a more precise classification of septic and aseptic prosthesis failure could be achieved before revision surgery.

Therefore, the aim of this study was to evaluate the diagnostic accuracy of this second-generation assay on synovial fluid specimens collected pre-operatively.

\section{Patients and methods}

The study protocol was approved by the institutional review board under reference no. 2544/09. Informed consent was obtained from every patient prior to screening. We used synovial fluid samples from a prospective cohort of patients who underwent revision surgery for total hip or knee arthroplasty at our institution in 2009 [37]. As per standard institutional procedure prior to arthroplasty revision, leukocyte count, Creactive protein (CRP), erythrocyte sedimentation rate (ESR), joint aspirate culture, and joint aspirate leukocyte count and differential were obtained from all patients. During surgery, tissue biopsies for culture and histology were obtained. After the collection of the specimens, one specimen of joint aspirate and one tissue biopsy per patient were frozen and stored at $-80{ }^{\circ} \mathrm{C}$ for further examination. Automated multiplex PCR analysis was performed as per the manufacturer's protocol after the specimens of joint fluid aspirate were thawed. The joint fluid sample was subjected to mechanical, thermal, chemical, and enzymatic lysis in a test tube for 30 minutes and then transferred into an "implant and tissue infection" (ITI) cartridge. The master mix, including deoxyribonucleic acid (DNA)-polymerase, primers, nucleotides and PCRbuffer, was added, and the cartridge was inserted into the Unyvero Analyser for the actual PCR. A result was reported as positive if an analyte reached the threshold of $10^{4}$ DNA fragments/pathogens $/ \mathrm{ml}$.

The patients enrolled were classified as either infected or aseptic after the histological and microbiological analysis of intraoperative tissue biopsies according to the standard then in use at our institution, which was implemented on the basis of the diagnostic criteria published by Zimmerli et al. [11]. Accordingly, a patient was classified as infected if there was a sinus tract present, if there was purulence around the joint or if a virulent organism was isolated in synovial fluid or tissue 


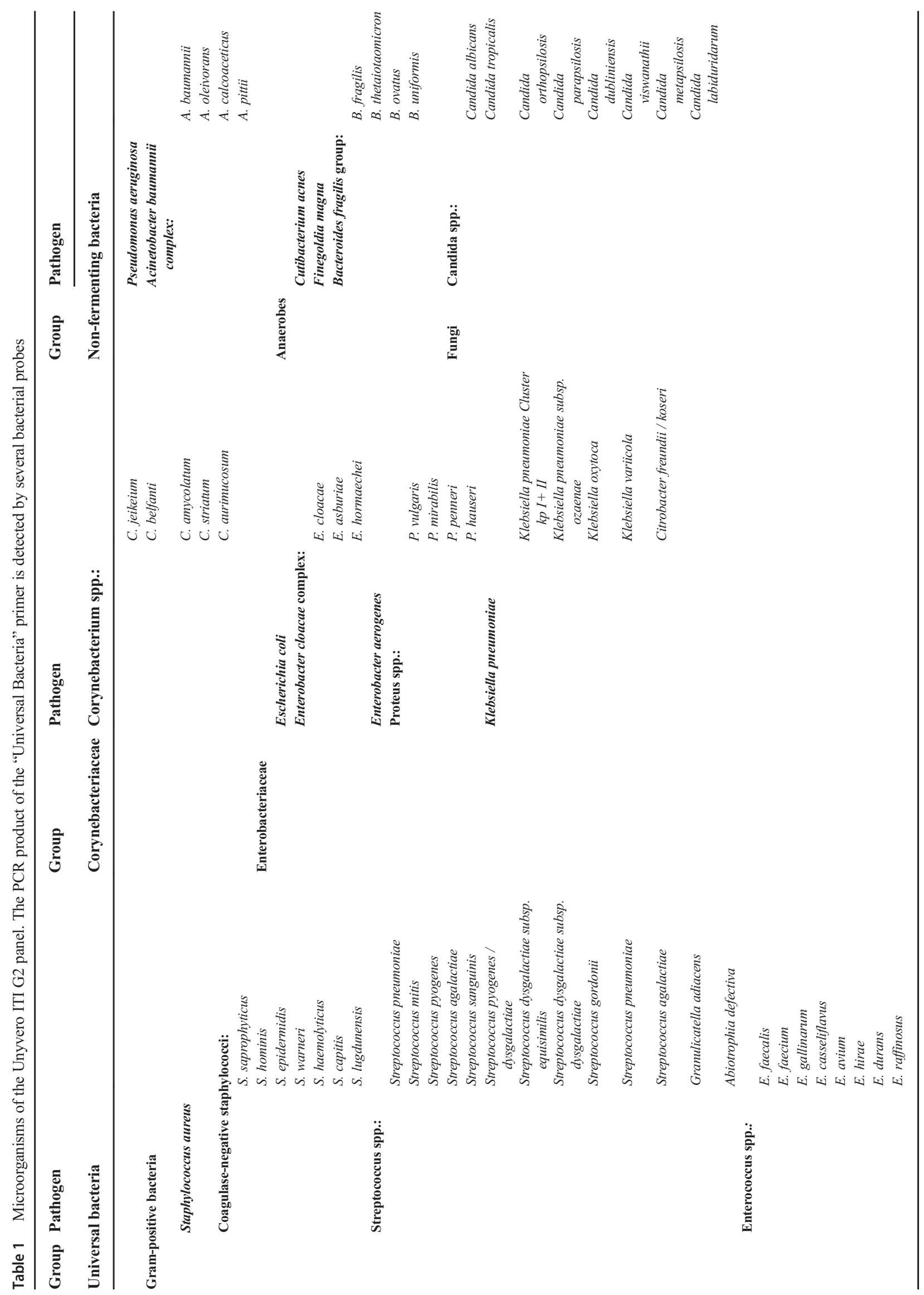


culture. Furthermore, a combination of any of the following findings led to the diagnosis of an infection: elevated serum CRP, blood leukocyte count or elevated ESR with the identification of a non-virulent organism in a joint fluid or tissue specimen, with positive histology as defined by Morawietz and Krenn [12], or the identification of a non-virulent organism with positive histology. This classification was used as the gold standard for the analysis of the diagnostic accuracy of the multiplex PCR.

For microbiological analysis, synovial fluid was cultivated on aerobic and anaerobic plates (Columbia sheep blood agar, Columbia chocolate agar, McConkey agar, Schädler anaerobic agar and Schädler KV anaerobic agar) and in liquid media (thioglycolate and glucose broth) at $37{ }^{\circ} \mathrm{C}$ in aerobic and anaerobic atmospheres. Media were checked for bacterial growth after 24 hours, 48 hours and ten days. Biochemical identification was performed with Vitek2 (bioMerieux, Nürtingen, Germany).

\section{Statistical analysis}

The patients' pre- and post-operative classification according to the diagnostic gold standard and the pre-operative diagnosis using multiplex PCR were recorded. Furthermore, the identified organisms and their respective resistance genes were collected and entered in an Excel table (Microsoft Corporation, Richmond, USA).

Absolute frequencies are given for categorical data, and the mean and minimum and maximum values are presented for age. Sensitivities, specificities, positive and negative predictive values as well as positive and negative likelihood ratios were estimated and presented. For sensitivity, specificity and predictive values, corresponding exact $95 \%$ confidence intervals were estimated based on the binomial distribution (Clopper-Pearson intervals [38]). For likelihood ratios, confidence intervals were estimated as described in [39]. All analyses were performed using the statistical software $R$ (version 3.6.0) and its library epiR $[40,41]$.

\section{Results}

Twenty-six patients ( 8 males, 18 females, 13 total hip arthroplasties, 13 total knee arthroplasties) with a mean age of 72.3 years (52.1-98.2 years) were included. PJI was diagnosed in 15 patients, and 11 patients were aseptic. The aseptic cases included four instances of aseptic loosening of total hip arthroplasties, four instances of aseptic loosening of total knee arthroplasties, two instances of malalignment in total knee arthroplasties, and one case of patella baja and arthrofibrosis in a total knee arthroplasty.
Table 2 Resistance gene markers of the Unyvero ITI G2 panel

\begin{tabular}{ll}
\hline Marker & Resistance \\
\hline ermA & Macrolides/lincosamides \\
ermC & Macrolides/lincosamides \\
mecA & Oxacillin/methicillin \\
mecC (LGA251) & Oxacillin/methicillin \\
vanA & Glycopeptides \\
vanB & Glycopeptides \\
aac(6')/aph(2") & Aminoglycosides \\
aacA4 & Aminoglycosides \\
ctx-M & 3rd-generation cephalosporin, class A \\
imp & Carbapenems, class B \\
kpc & Carbapenems, class B \\
ndm & Carbapenems, class B \\
oxa-23 & Carbapenems, class D \\
oxa-24/40 & Carbapenems, class D \\
oxa-48 & Carbapenems, class D \\
oxa-58 & Carbapenems, class D \\
vim & Carbapenems, class B \\
\hline
\end{tabular}

Of the 15 cases of infection, five had been misdiagnosed as aseptic preoperatively. In each case, the diagnosis was changed due to the additional intra-operative findings.

Joint fluid aspirates showed growth on conventional culture media in ten out of 15 PJI cases and in one of the 11 aseptic cases, yielding a sensitivity of $0.67(0.23,0.63)$ and a specificity of $0.91(0.59,1.00)$. In three of the five falsenegative PJI cases, the organism that was later identified in intra-operative tissue biopsy culture could be identified via joint fluid multiplex PCR. There was one false-positive classification due to the growth of Staphylococcus aureus in the joint aspirate culture before surgery. This finding was not confirmed in later tissue biopsy cultures or histology.

Multiplex PCR identified pathogens in 12 out of 15 PJI cases and in none of the aseptic cases. This resulted in a sensitivity of $0.8(0.52,0.96)$ and a specificity of $1.0(0.69,1.0)$. Two of the PJI cases in which multiplex PCR failed to identify any organism also did not show any growth in conventional synovial fluid culture. The remaining false-negative PJI case showed the growth of group B streptococci in conventional culture of the synovial fluid as well as intra-operative tissue biopsies. For an overview of the positive and negative predictive values and likelihood ratios of joint fluid culture and joint fluid PCR, respectively, see Table 3.

Multiplex PCR analysis identified resistance genes in five of the 12 detected pathogens. The mecA gene mediating methicillin resistance was found three times in coagulase-negative staphylococci. The ermC and ermA genes were found in coagulase-negative staphylococci and S. aureus, respectively. 
Table 3 Overview of patient data, affected joint, preoperative and postoperative classification, diagnosis, and identified bacteria

\begin{tabular}{|c|c|c|c|c|c|c|c|c|c|}
\hline $\begin{array}{l}\text { Patient } \\
\text { no. }\end{array}$ & $\begin{array}{l}\text { Age } \\
\text { (years) }\end{array}$ & Sex & $\begin{array}{l}\text { Hip/ } \\
\text { knee }\end{array}$ & $\begin{array}{l}\text { Pre-operative } \\
\text { classification }\end{array}$ & Diagnosis & $\begin{array}{l}\text { Preoperative } \\
\text { PCR }\end{array}$ & SF culture & SF PCR & Biopsy culture \\
\hline 1 & 80.1 & f & Hip & PJI & PJI & PJI & S. epidermidis & $C N S$ & $\begin{array}{l}\text { S. epidermidis, } \\
\text { S. hominis }\end{array}$ \\
\hline 2 & 54.1 & f & Hip & Aseptic loosening & PJI & PJI & - & $C N S$ & CNS \\
\hline 3 & 52.1 & $\mathbf{m}$ & Knee & PJI & PJI & PJI & $C N S$ & $C N S$ & $C N S$ \\
\hline 4 & 98.2 & f & Knee & PJI & PJI & PJI & S. epidermidis & $C N S$ & S. epidermidis \\
\hline 5 & 78.4 & f & Knee & Aseptic loosening & PJI & Aseptic & - & - & CNS \\
\hline 6 & 66.7 & m & Hip & PJI & PJI & PJI & 2 strains $C N S$ & $\begin{array}{l}\text { CNS, Cutibacterium } \\
\text { acnes }\end{array}$ & 2 strains $S$. epidermidis \\
\hline 7 & 60.9 & $\mathbf{m}$ & Hip & $\begin{array}{l}\text { Heterotopic } \\
\quad \text { ossification }\end{array}$ & PJI & PJI & - & $C N S$ & S. epidermidis \\
\hline 8 & 84.9 & m & Hip & PJI & PJI & PJI & $\begin{array}{l}\text { Listeria } \\
\quad \text { monocytogenes }\end{array}$ & $C N S$ & Listeria monocytogenes \\
\hline 9 & 66 & f & Knee & PJI & PJI & PJI & S. aureus & S. aureus & S. aureus \\
\hline 10 & 82.2 & f & Hip & PJI & PJI & PJI & S. aureus & S. aureus & S. aureus \\
\hline 11 & 52.5 & f & Knee & Aseptic loosening & PJI & Aseptic & - & - & CNS \\
\hline 12 & 75.6 & f & Hip & Aseptic loosening & PJI & PJI & - & CNS & $C N S$ \\
\hline 13 & 78.2 & f & Knee & PJI & PJI & PJI & $\begin{array}{c}\text { Streptococcus } \\
\text { salivarius }\end{array}$ & Streptococcus spp. & $\begin{array}{l}\text { Streptococcus } \\
\text { salivarius }\end{array}$ \\
\hline 14 & 60.8 & m & Hip & PJI & PJI & PJI & $\begin{array}{l}\text { Group B } \\
\quad \text { Streptococci }\end{array}$ & $\begin{array}{c}\text { Streptococcus } \\
\text { agalactiae }\end{array}$ & - \\
\hline 15 & 83.3 & f & Hip & PJI & PJI & Aseptic & $\begin{array}{l}\text { Group B } \\
\quad \text { Streptococci }\end{array}$ & - & Group B Streptococci \\
\hline 16 & 81.7 & f & Hip & Aseptic loosening & Aseptic loosening & Aseptic & - & - & - \\
\hline 17 & 73.5 & f & Knee & Malalignment & Malalignment & Aseptic & - & - & - \\
\hline 18 & 77 & f & Knee & Aseptic loosening & Aseptic loosening & Aseptic & - & - & - \\
\hline 19 & 71 & $\mathbf{m}$ & Knee & Aseptic loosening & Aseptic loosening & Aseptic & - & - & - \\
\hline 20 & 77.4 & f & Knee & Malalignment & Malalignment & Aseptic & - & - & - \\
\hline 21 & 83.2 & f & Knee & Aseptic loosening & Aseptic loosening & Aseptic & - & - & - \\
\hline 22 & 79.2 & f & Hip & Aseptic loosening & Aseptic loosening & Aseptic & - & - & - \\
\hline 23 & 64.1 & $\mathbf{m}$ & Hip & Aseptic loosening & Aseptic loosening & Aseptic & - & - & - \\
\hline 24 & 59 & f & Knee & Aseptic loosening & Aseptic loosening & Aseptic & - & - & - \\
\hline 25 & 67.8 & $\mathbf{m}$ & Knee & Arthrofibrosis & Arthrofibrosis & Aseptic & - & - & - \\
\hline 26 & 74 & f & Hip & PJI & Aseptic loosening & Aseptic & S. aureus & - & - \\
\hline
\end{tabular}

$S F$ synovial fluid

Both genes are resistance markers for macrolides and lincosamides. Phenotypical susceptibility testing confirmed all genotypically detected antibiotic resistances. Apart from the ones detected by PCR, there were no clinically relevant phenotypical resistances.

There were some discrepancies between the positive culture and PCR results. In one case, the growth of Listeria monocytogenes in fluid culture was found, while PCR was positive for coagulase-negative staphylococci (CNS). In the subsequent tissue culture, the growth of Listeria monocytogenes was confirmed, but not of CNS. In another case, fluid culture exhibited the growth of two strains of CNS, both later confirmed in tissue biopsies. Unyvero PCR, however, was positive for CNS and $C$. acnes. For an overview of the results, see Table 4.

\section{Discussion}

In our study, multiplex PCR of joint fluid aspirate specimens showed superior diagnostic accuracy to that of conventional culture, even when used on previously frozen and stored fluid specimens. If the method had been used at the time of the sample collection, three patients would have been correctly diagnosed with PJI based on pre-operative PCR results in joint fluid. Instead, the pre-operative diagnosis had to be changed after the results from intra-operative tissue cultures became known. Conversely, there was one false-negative result using the method on joint fluid.

The sensitivity and specificity of joint fluid aspirate culture in this study are comparable to those of reliable reports in the available literature (sensitivity $0.72-0.8$ and specificity 0.93 $0.95)[26,42-44]$. As joint fluid aspirate culture is currently the only widely applied means to pre-operatively identify the infectious agent causing PJI, the relatively low sensitivities in these reports underline our argument for additional or improved methods of detection.

Failure to detect the organism causing infection leads to the constellation of culture-negative PJI, which is challenging to treat [45]. The rate of culture-negative infections varies in the available literature, but it is considerable, ranging as high as $42 \%$ [46]. The ramifications of culture-negative PJI for the treatment strategy and the outcome are equivocal in most 
Table 4 Overview of the diagnostic parameters (with 95\% confidence intervals) of joint fluid culture and multiplex PCR

\begin{tabular}{|c|c|c|c|c|c|c|c|c|c|c|}
\hline Test & $\begin{array}{l}\text { True } \\
\text { positive }\end{array}$ & $\begin{array}{l}\text { False } \\
\text { positive }\end{array}$ & $\begin{array}{l}\text { True } \\
\text { negative }\end{array}$ & $\begin{array}{l}\text { False } \\
\text { negative }\end{array}$ & Sensitivity & Specificity & PPV & NPV & LR+ & LR- \\
\hline Joint fluid culture & 10 & 1 & 10 & 5 & $\mathbf{0 . 6 7}(0.23,0.63)$ & $\mathbf{0 . 9 1}(0.59,1.00)$ & $\mathbf{0 . 9 1}(0.59,1.00)$ & $\mathbf{0 . 6 7}(0.38,0.88)$ & $7.33(1.09,49.16)$ & $\mathbf{0 . 3 7}(0.17,0.77)$ \\
\hline $\begin{array}{l}\text { Joint fluid } \\
\text { multiplex PCR }\end{array}$ & 12 & 0 & 11 & 3 & $\mathbf{0 . 8}(0.52,0.96)$ & $\mathbf{1 . 0}(0.69,1.0)$ & $\mathbf{1 . 0}(0.74,1.0)$ & $\mathbf{0 . 7 7}(0.46,0.95)$ & $\mathbf{n} / \mathbf{a}$ & $0.2(0.07,0.55)$ \\
\hline
\end{tabular}

$P P V$ positive predictive value; $N P V$ negative predictive value; $L R+$ positive likelihood ratio; $L R$ - negative likelihood ratio

reports, with some authors even postulating a higher success rate when the causative microbe is unknown [47-49]. In fact, culture-negative PJI caused by fastidious organisms such as $S$. epidermidis and $C$. acnes might be successfully treated using the right empirical antibiotic regimen. However, when culture-negative PJI is caused by fungi, mycobacteria or other unusual agents, empirical therapy is likely to fail. This likelihood is reflected in a more recent study that found an impaired treatment success rate when the agent was unknown [50]. The authors concluded that the pre-operative identification of the underlying organism was paramount to successful treatment and should be pursued unconditionally.

In our opinion, the weakness of the currently accepted diagnostic standard lies in the low sensitivity of synovial fluid culture. As a result, both culture-negative PJI and falsely diagnosed "aseptic" loosening limit our treatment outcomes. The results of our study suggest that the diagnostic accuracy of pathogen detection in joint fluid can be ameliorated using multiplex PCR.

Unyvero multiplex PCR has been used on synovial fluid specimens before. Morgenstern et al. reported a slightly inferior sensitivity and specificity of multiplex PCR used in synovial fluid samples from 142 patients when compared to our findings [25]. However, they were using the first-generation Unyvero ITI cartridge. Our use of the second-generation cartridge might explain the results reported here. Lausmann et al. published results of the same first-generation test used on synovial aspirates from 60 patients, including patients with acute PJI [30]. Their reported sensitivity and specificity of 0.79 and 1.0, respectively, are comparable to our results. However, the inclusion of acute PJI cases is likely to have increased the diagnostic accuracy, as the much higher bacterial burden in acute PJI cases is more likely to be detected. In general, acute PJI is fairly easy to diagnose, and the identification of the causative agent by joint aspirate culture is reliable in those cases. Therefore, we focused on low-grade PJI, where the correct diagnosis and microbe identification often prove to be difficult, especially with the limited material obtainable pre-operatively via joint aspiration.

Conventional and multiplex PCR have been used on sonication fluid to improve the intra-operative capabilities of microbe identification. In a recent meta-analysis, neither method was shown to be superior to sonication fluid culture [27, 51]. In our view, this underscores the fact that the combination of all pre-operative and intra-operative criteria yields a high diagnostic value, and the well-established diagnostic algorithms barely need improvement $[10,26]$. However, the pre-operative workup for the exclusion of low-grade infections based on serum inflammation markers and joint aspiration could profit from the implementation of molecular methods for microbe detection.

There were two discrepancies between the results of the PCR and those of conventional culture worth discussing. First, both conventional cultures of joint fluid and tissue biopsies exhibited infection with Listeria monocytogenes in one case. While the PCR failed to detect the same organism, it was positive for CNS. Interestingly, it is one of only two instances with a low signal intensity in the PCR. Furthermore, Listeria monocytogenes is not included in the Unyvero ITI panel of organisms; therefore, it could not have been correctly detected by it. Whether the positive result showing CNS was caused by sample contamination or the presence of coagulase-negative staphylococci undetected by conventional means is unclear. In the second discrepancy seen, conventional cultures of joint fluid and tissue biopsies detected two different strains of $S$. epidermidis in one patient. While Unyvero is per se unable to discern different strains of the same organism, it did show CNS and, in addition, Cutibacterium acnes. Again, whether this constitutes a relevant finding, a contamination, or a falsepositive result remains unclear. Accordingly, we considered the detection of CNS a true positive result. Due to the fastidiousness of $C$. acnes, it is a possible scenario that the conventional culture failed to detect its presence. In that case, the PCR result would be a true positive.

We reported one patient pre-operatively classified as infected due to the growth of $S$. aureus in the joint aspirate culture who was later deemed to be aseptic. By default, any detection of a highly virulent agent such as $S$. aureus is considered to prove the presence of an infection. The patient was treated with a two-stage prosthesis exchange. However, there were no positive intra-operative biopsies, and the histological results were negative. Therefore, despite convention, we considered the patient to have been aseptic in retrospect.

There are some limitations of this study. First, while patient recruitment and pre-operative and intra-operative conventional diagnostics were performed prospectively, multiplex PCR analysis was performed on stored specimens 
retrospectively. While this restricts data quality, it might also have resulted in reduced specimen quality and hence poorer performance of the PCR. Specimen freezing and thawing leads to more viscous fluid samples, which need to be diluted in some instances [52]. Where the bacterial load is low, this dilution might lower the DNA count below the detection threshold and cause false-negative results. Apart from that, tests performed by the manufacturer showed no effects on pathogen detection after 1 year of storage at $-70{ }^{\circ} \mathrm{C}$ of both native and artificial spiked samples. In our collective, only one viscous sample had to be diluted, and it still yielded a positive result. As there were no false-negative readings in this study, we assume that the freezing and thawing of samples had no sizable detrimental effects.

Second, the diagnostic gold standard used in our institution in 2009, even though similar to the currently established standards, is dated. Applying one of today's established diagnostic algorithms might change the results of our evaluation. However, there are currently several diagnostic algorithms for prosthetic joint infections existing in parallel. All of them have been and are still subject to changes and amendments; therefore, it remains problematic to define a gold standard when evaluating a new testing method. Even within the framework of a defined standard, "new" diagnostic tools, such as sonication, alpha-defensin or any DNA-based assays, are difficult to judge. As the diagnosis is established under the consideration of various factors, they will serve as a more or less meaningful amendment to what is already known.

Being well aware of the gold standard problem, we would like to emphasize that there is a requirement to improve our ability not just to diagnose PJI but also to identify the agent causing it before a treatment is initiated. Based on our findings, multiplex PCR could represent a useful tool for just that. Using multiplex PCR on aspirated joint fluid might prove very helpful in addition to joint aspirate culture to increase the chance of pathogen identification before surgery.

Authors' contributions Conception and design of the study: C. Suren, P. M. Prodinger, S. Feihl.

Generation, collection of the data: C. Suren, S. Cabric, I.J. Banke, P. M. Prodinger, A. Trampuz.

Assembly, analysis and/or interpretation of the data: B. Haller, C. Suren, S. Feihl, A. Trampuz.

Drafting and revising the manuscript: C. Suren, P. M. Prodinger, I. J. Banke, R. von Eisenhart-Rothe.

Funding information This study was supported with a grant by the German Knee Society (Deutsche Kniegesellschaft, DKG). Open Access funding provided by Projekt DEAL.

\section{Compliance with ethical standards}

Conflict of interest On behalf of all authors, the corresponding author states that there is no conflict of interest.
Research involving human participants and/or animals This original research is based on data obtained from human participants.

Informed consent Informed consent was given by every participant prior to being included in the study.

Approval of the final version of the manuscript All authors read and approved the final manuscript.

Open Access This article is licensed under a Creative Commons Attribution 4.0 International License, which permits use, sharing, adaptation, distribution and reproduction in any medium or format, as long as you give appropriate credit to the original author(s) and the source, provide a link to the Creative Commons licence, and indicate if changes were made. The images or other third party material in this article are included in the article's Creative Commons licence, unless indicated otherwise in a credit line to the material. If material is not included in the article's Creative Commons licence and your intended use is not permitted by statutory regulation or exceeds the permitted use, you will need to obtain permission directly from the copyright holder. To view a copy of this licence, visit http://creativecommons.org/licenses/by/4.0/.

\section{References}

1. Parvizi J, Della Valle CJ (2010) AAOS clinical practice guideline: diagnosis and treatment of periprosthetic joint infections of the hip and knee. J Am Acad Orthop Surg 18(12):771-772

2. Parvizi J, Gehrke T, Chen AF (2013) Proceedings of the international consensus on periprosthetic joint infection. Bone Joint $\mathrm{J} 95-$ B(11):1450-1452. https://doi.org/10.1302/0301-620X.95B11. 33135

3. Parvizi J, Zmistowski B, Berbari EF, Bauer TW, Springer BD, Della Valle CJ, Garvin KL, Mont MA, Wongworawat MD, Zalavras CG (2011) New definition for periprosthetic joint infection: from the workgroup of the musculoskeletal infection society. Clin Orthop Relat Res 469(11):2992-2994. https://doi.org/10.1007/s11999011-2102-9

4. Parvizi J, Adeli B, Zmistowski B, Restrepo C, Greenwald AS (2012) Management of periprosthetic joint infection: the current knowledge: AAOS exhibit selection. J Bone Joint Surg Am 94(14):e104. https://doi.org/10.2106/jbjs.k.01417

5. Horan TC, Gaynes RP, Martone WJ, Jarvis WR, Emori TG (1992) CDC definitions of nosocomial surgical site infections, 1992: a modification of CDC definitions of surgical wound infections. Infect Control Hosp Epidemiol 13(10):606-608

6. Berbari EF, Marculescu C, Sia I, Lahr BD, Hanssen AD, Steckelberg JM, Gullerud R, Osmon DR (2007) Culture-negative prosthetic joint infection. Clin Infect Dis 45(9):1113-1119. https:// doi.org/10.1086/522184

7. Trampuz A, Steinrucken J, Clauss M, Bizzini A, Furustrand U, Uckay I, Peter R, Bille J, Borens O (2010) New methods for the diagnosis of implant-associated infections. Rev Med Suisse 6(243): 731-734

8. Dramis A, Aldlyami E, Grimer RJ, Dunlop DJ, O'Connell N, Elliott $\mathrm{T}$ (2009) What is the significance of a positive propionibacterium acnes culture around a joint replacement? Int Orthop 33(3):829833. https://doi.org/10.1007/s00264-008-0534-y

9. Parvizi J (2011) New definition for periprosthetic joint infection. Am J Orthop (Belle Mead NJ) 40(12):614-615

10. Parvizi J, Tan TL, Goswami K, Higuera C, Della Valle C, Chen AF, Shohat N (2018) The 2018 definition of Periprosthetic hip and knee infection: an evidence-based and validated criteria. J Arthroplasty 
33(5):1309-1314.e1302. https://doi.org/10.1016/j.arth.2018.02. 078

11. Zimmerli W, Trampuz A, Ochsner PE (2004) Prosthetic-joint infections. N Engl J Med 351(16):1645-1654. https://doi.org/10.1056/ NEJMra040181

12. Morawietz L, Classen RA, Schroder JH, Dynybil C, Perka C, Skwara A, Neidel J, Gehrke T, Frommelt L, Hansen T, Otto M, Barden B, Aigner T, Stiehl P, Schubert T, Meyer-Scholten C, Konig A, Strobel P, Rader CP, Kirschner S, Lintner F, Ruther W, Bos I, Hendrich C, Kriegsmann J, Krenn V (2006) Proposal for a histopathological consensus classification of the periprosthetic interface membrane. J Clin Pathol 59(6):591-597. https://doi.org/10.1136/ jcp.2005.027458

13. Yan Q, Karau MJ, Greenwood-Quaintance KE, Mandrekar JN, Osmon DR, Abdel MP, Patel R (2018) Comparison of diagnostic accuracy of periprosthetic tissue culture in blood culture bottles to that of prosthesis sonication fluid culture for diagnosis of prosthetic joint infection (PJI) by use of Bayesian latent class modeling and IDSA PJI criteria for classification. J Clin Microbiol 56(6). https:// doi.org/10.1128/jcm.00319-18

14. Trampuz A, Piper KE, Jacobson MJ, Hanssen AD, Unni KK, Osmon DR, Mandrekar JN, Cockerill FR, Steckelberg JM, Greenleaf JF, Patel R (2007) Sonication of removed hip and knee prostheses for diagnosis of infection. N Engl J Med 357(7):654 663. https://doi.org/10.1056/NEJMoa061588

15. Saleh A, Guirguis A, Klika AK, Johnson L, Higuera CA, Barsoum WK (2014) Unexpected positive intraoperative cultures in aseptic revision arthroplasty. J Arthroplast 29(11):2181-2186. https://doi. org/10.1016/j.arth.2014.07.010

16. Trampuz A, Zimmerli W (2005) Prosthetic joint infections: update in diagnosis and treatment. Swiss Med Wkly 135(17-18):243-251 Doi:2005/17/smw-10934

17. Darouiche RO (2004) Treatment of infections associated with surgical implants. N Engl J Med 350(14):1422-1429. https://doi.org/ 10.1056/NEJMra035415

18. Boddapati V, Fu MC, Mayman DJ, Su EP, Sculco PK, McLawhorn AS (2018) Revision total knee arthroplasty for periprosthetic joint infection is associated with increased postoperative morbidity and mortality relative to noninfectious revisions. J Arthroplast 33(2): 521-526. https://doi.org/10.1016/j.arth.2017.09.021

19. Kreft R, Costerton J, Ehrlich GPCR Is changing clinical diagnostics. Microbe Mag. https://doi.org/10.1128/microbe.8.15.1

20. Gallo J, Kolar M, Dendis M, Loveckova Y, Sauer P, Zapletalova J, Koukalova D (2008) Culture and PCR analysis of joint fluid in the diagnosis of prosthetic joint infection. New Microbiol 31(1):97104

21. Sebastian S, Malhotra R, Sreenivas V, Kapil A, Chaudhry R, Dhawan B (2018) Utility of 16S rRNA PCR in the synovial fluid for the diagnosis of prosthetic joint infection. Ann Lab Med 38(6): 610-612. https://doi.org/10.3343/alm.2018.38.6.610

22. Portillo ME, Salvado M, Sorli L, Alier A, Martinez S, Trampuz A, Gomez J, Puig L, Horcajada JP (2012) Multiplex PCR of sonication fluid accurately differentiates between prosthetic joint infection and aseptic failure. J Inf Secur 65(6):541-548. https://doi.org/10.1016/j. jinf.2012.08.018

23. Hu FZ, Ehrlich GD, Post JC, Nistico L, Kreft R, Kathju S, Costerton JW, Stoodley P, Hall-Stoodley L, Maale G, James G, Sotereanos N, DeMeo P (2011) New methods for the detection of orthopedic and other biofilm infections. FEMS Immunol Med Microbiol 61(2):133-140. https://doi.org/10.1111/j.1574-695X. 2010.00766.x

24. Dora C, Altwegg M, Gerber C, Böttger EC, Zbinden R (2008) Evaluation of conventional microbiological procedures and molecular genetic techniques for diagnosis of infections in patients with implanted orthopedic devices. J Clin Microbiol 46(2):824-825. https://doi.org/10.1128/jcm.01227-07
25. Morgenstern C, Cabric S, Perka C, Trampuz A, Renz N (2018) Synovial fluid multiplex PCR is superior to culture for detection of low-virulent pathogens causing periprosthetic joint infection. Diagn Microbiol Infect Dis 90(2):115-119. https://doi.org/10. 1016/j.diagmicrobio.2017.10.016

26. Izakovicova P, Borens O, Trampuz A (2019) Periprosthetic joint infection: current concepts and outlook. EFORT Open Rev 4(7): 482-494. https://doi.org/10.1302/2058-5241.4.180092

27. Liu K, Fu J, Yu B, Sun W, Chen J, Hao L (2018) Meta-analysis of sonication prosthetic fluid PCR for diagnosing periprosthetic joint infection. PLoS One 13(4):e0196418. https://doi.org/10.1371/ journal.pone. 0196418

28. Muhlhofer HM, Pohlig F, Kanz KG, Lenze U, Lenze F, Toepfer A, Kelch S, Harrasser N, von Eisenhart-Rothe R, Schauwecker J (2017) Prosthetic joint infection development of an evidencebased diagnostic algorithm. Eur J Med Res 22(1):8. https://doi. org/10.1186/s40001-017-0245-1

29. Muhlhofer HM, Kanz KG, Pohlig F, Lenze U, Lenze F, Toepfer A, von Eisenhart-Rothe R, Schauwecker J (2017) Implementation of an algorithm for prosthetic joint infection: deviations and problems. Surg Infect 18(2):164-169. https://doi.org/10.1089/sur.2015.208

30. Lausmann C, Zahar A, Citak M, Branes J, Schmidl S, Frommelt L, Gehrke T, Gebauer M (2017) Are there benefits in early diagnosis of prosthetic joint infection with multiplex polymerase chain reaction? J Bone Jt Infect 2(4):175-183. https://doi.org/10.7150/jbji. 22062

31. Borde JP, Hacker GA, Guschl S, Serr A, Danner T, Hubner J, Burrack-Lange S, Ludke G, Helwig P, Hauschild O, Kern WV (2015) Diagnosis of prosthetic joint infections using UMDuniversal kit and the automated multiplex-PCR Unyvero i60 ITI((R)) cartridge system: a pilot study. Infection 43(5):551-560. https://doi.org/10.1007/s15010-015-0796-4

32. Hischebeth GT, Randau TM, Buhr JK, Wimmer MD, Hoerauf A, Molitor E, Bekeredjian-Ding I, Gravius S (2016) Unyvero 160 implant and tissue infection (ITI) multiplex PCR system in diagnosing periprosthetic joint infection. J Microbiol Methods 121:27-32. https://doi.org/10.1016/j.mimet.2015.12.010

33. Malandain D, Bemer P, Leroy AG, Leger J, Plouzeau C, Valentin AS, Jolivet-Gougeon A, Tande D, Hery-Arnaud G, Lemarie C, Kempf M, Bret L, Burucoa C, Corvec S (2018) Assessment of the automated multiplex-PCR Unyvero i60 ITI((R)) cartridge system to diagnose prosthetic joint infection: a multicentre study. Clin Microbiol Infect 24(1):83.e81-83.e86. https://doi.org/10.1016/j. cmi.2017.05.017

34. Prieto-Borja L, Rodriguez-Sevilla G, Aunon A, Perez-Jorge C, Sandoval E, Garcia-Canete J, Gadea I, Fernandez-Roblas R, Blanco A, Esteban J (2017) Evaluation of a commercial multiplex PCR (Unyvero i60((R))) designed for the diagnosis of bone and joint infections using prosthetic-joint sonication. Enferm Infecc Microbiol Clin 35(4):236-242. https://doi.org/10.1016/j.eimc. 2016.09.007

35. Renz N, Feihl S, Cabric S, Trampuz A (2017) Performance of automated multiplex PCR using sonication fluid for diagnosis of periprosthetic joint infection: a prospective cohort. Infection 45(6): 877-884. https://doi.org/10.1007/s15010-017-1073-5

36. Sigmund IK, Windhager R, Sevelda F, Staats K, Puchner SE, Stenicka S, Thalhammer F, Holinka J (2018) Multiplex PCR Unyvero i60 ITI application improves detection of low-virulent microorganisms in periprosthetic joint infections. Int Orthop. https://doi.org/10.1007/s00264-018-4136-z

37. Gollwitzer H, Dombrowski Y, Prodinger PM, Peric M, Summer B, Hapfelmeier A, Saldamli B, Pankow F, von Eisenhart-Rothe R, Imhoff AB, Schauber J, Thomas P, Burgkart R, Banke IJ (2013) Antimicrobial peptides and proinflammatory cytokines in periprosthetic joint infection. J Bone Joint Surg Am 95(7):644651. https://doi.org/10.2106/jbjs.L.00205 
38. Clopper CJ, Pearson ES (1934) The use of confidence or fiducial limits illustrated in the case of the binomial. Biometrika 26(4):404 413. https://doi.org/10.2307/2331986

39. Simel DL, Samsa GP, Matchar DB (1991) Likelihood ratios with confidence: sample size estimation for diagnostic test studies. J Clin Epidemiol 44(8):763-770. https://doi.org/10.1016/0895-4356(91) 90128-v

40. R Core Team (2019) R: a language and environment for statistical computing. R Foundation for Statistical Computing, Vienna https:// www.R-project.org/

41. Mark Stevenson with contributions from Telmo Nunes CH, Jonathon Marshall, Javier Sanchez, Ron Thornton, Jeno Reiczigel, Jim Robison-Cox, Paola Sebastiani, Peter Solymos, Kazuki Yoshida, Geoff Jones, Sarah Pirikahu, Simon Firestone, Ryan Kyle, Johann Popp, Mathew Jay and Charles Reynard (2019) epiR: tools for the analysis of epidemiological data. R package version 1.0-4. https://CRAN.R-project.org/package=epiR)

42. Qu X, Zhai Z, Wu C, Jin F, Li H, Wang L, Liu G, Liu X, Wang W, Li H, Zhang X, Zhu Z, Dai K (2013) Preoperative aspiration culture for preoperative diagnosis of infection in total hip or knee arthroplasty. J Clin Microbiol 51(11):3830-3834. https://doi.org/ 10.1128/jcm.01467-13

43. Fink B, Makowiak C, Fuerst M, Berger I, Schafer P, Frommelt L (2008) The value of synovial biopsy, joint aspiration and C-reactive protein in the diagnosis of late peri-prosthetic infection of total knee replacements. J Bone Joint Surg Br 90(7):874-878. https://doi.org/ 10.1302/0301-620X.90B7.20417

44. Della Valle CJ, Sporer SM, Jacobs JJ, Berger RA, Rosenberg AG, Paprosky WG (2007) Preoperative testing for sepsis before revision total knee arthroplasty. J Arthroplast 22(6 Suppl 2):90-93. https:// doi.org/10.1016/j.arth.2007.04.013

45. Mortazavi SM, Vegari D, Ho A, Zmistowski B, Parvizi J (2011) Two-stage exchange arthroplasty for infected total knee arthroplasty: predictors of failure. Clin Orthop Relat Res 469(11): 3049-3054. https://doi.org/10.1007/s11999-011-2030-8
46. Palan J, Nolan C, Sarantos K, Westerman R, King R, Foguet $P$ (2019) Culture-negative periprosthetic joint infections. EFORT Open Rev 4(10):585-594. https://doi.org/10.1302/2058-5241.4. 180067

47. Berbari EF, Osmon DR, Duffy MC, Harmssen RN, Mandrekar JN, Hanssen AD, Steckelberg JM (2006) Outcome of prosthetic joint infection in patients with rheumatoid arthritis: the impact of medical and surgical therapy in 200 episodes. Clin Infect Dis 42(2):216223. https://doi.org/10.1086/498507

48. Huang R, Buckley PS, Scott B, Parvizi J, Purtill JJ (2015) Administration of aspirin as a prophylaxis agent against venous thromboembolism results in lower incidence of periprosthetic joint infection. J Arthroplast 30(9 Suppl):39-41. https://doi.org/10.1016/ j.arth.2015.07.001

49. Li H, Ni M, Li X, Zhang Q, Li X, Chen J (2017) Two-stage revisions for culture-negative infected total knee arthroplasties: a fiveyear outcome in comparison with one-stage and two-stage revisions for culture-positive cases. J Orthop Sci 22(2):306-312. https://doi. org/10.1016/j.jos.2016.11.008

50. Tan TL, Kheir MM, Shohat N, Tan DD, Kheir M, Chen C, Parvizi J (2018) Culture-negative periprosthetic joint infection: an update on what to expect. JB JS Open Access 3(3):e0060. https://doi.org/10. 2106/jbjs.Oa.17.00060

51. Liu H, Zhang Y, Li L, Zou HC (2017) The application of sonication in diagnosis of periprosthetic joint infection. Eur J Clin Microbiol Infect Dis 36(1):1-9. https://doi.org/10.1007/s10096-016-2778-6

52. Samadi Shams S, Zununi Vahed S, Soltanzad F, Kafil V, Barzegari A, Atashpaz S, Barar J (2011) Highly effective DNA extraction method from fresh, frozen, dried and clotted blood samples. BioImpacts : BI 1(3):183-187. https://doi.org/10.5681/bi.2011.025

Publisher's note Springer Nature remains neutral with regard to jurisdictional claims in published maps and institutional affiliations. 